\title{
En hommage à mon amie Michelle Sommers, cette petite histoire vraie
}

\section{Nicole Toffoletti}

\section{(2) OpenEdition}

\section{Journals}

Édition électronique

URL : http://journals.openedition.org/esp/678

DOI : 10.4000/esp.678

ISSN : 2532-0319

Éditeur

Centre d'Information sur l'Éducation Bilingue et Plurilingue

\section{Édition imprimée}

Date de publication : 1 décembre 2015

Pagination : 101-103

ISSN : 1127-266X

\section{Référence électronique}

Nicole Toffoletti, «En hommage à mon amie Michelle Sommers, cette petite histoire vraie ", Éducation et sociétés plurilingues [En ligne], 39 | 2015, mis en ligne le 01 octobre 2016, consulté le 15 septembre 2020. URL : http://journals.openedition.org/esp/678 


\section{EN HOMMAGE À MON AMIE MICHELLE SOMMERS, CETTE PETITE HISTOIRE VRAIE}

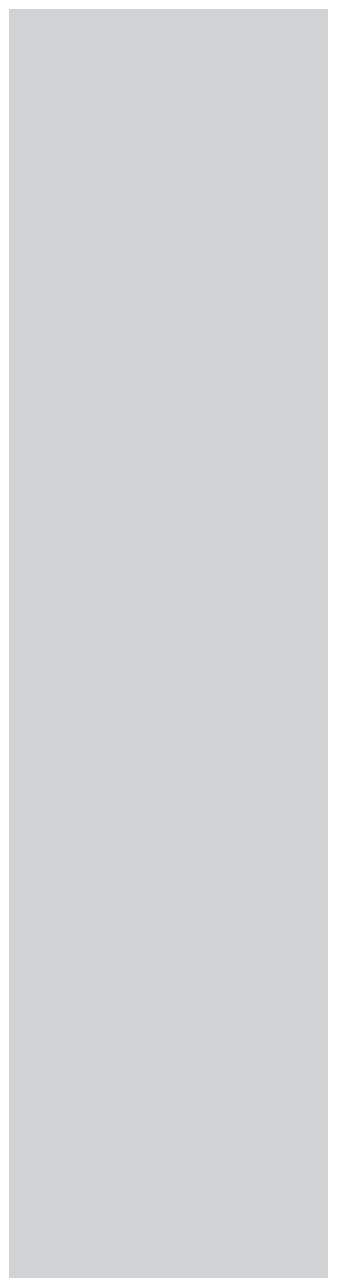

\section{Nicole TofFoletTI}

$\mathrm{M}$ on père Louis Toffoletti, est né le 11 mai 1902 à Faedis, province de Udine, au nord-est de l'Italie, dans une famille de onze enfants. Son père Marcellino travaillait épisodiquement en Autriche, vraisemblablement comme ouvrier agricole ou bûcheron. La famille était très pauvre.

À vingt ans, après son service militaire, Louis a quitté l'Italie avec quelques membres de sa famille et d'autres personnes pour venir en France.

Comment ce petit groupe est arrivé jusque dans les Ardennes, nous ne le savons pas. Mon oncle et ma tante (la sœur de mon père ) s'y sont installés, ont eu des enfants, des petits enfants, que nous avons connus et qui ont fait leur vie dans cette région. Ma cousine germaine Henriette, décédée l'an passé, était le lien entre les "ardennais" et nous. Sa sœur Hélène, née en Italie, avait été confiée aux grands parents italiens au départ des parents pour la France; elle n'y a jamais vécu mais est revenue en visite bien plus tard.

Mon père n'est pas resté dans le nord, il est descendu vers Lyon et Saint Étienne, puis est arrivé à Saint Cyr les Vignes où il travaillait. Il y a rencontré ma mère, s'est marié, a eu cinq enfants tous nés dans ce petit village, berceau de la famille de ma mère depuis des générations.

Nous n'avons jamais évoqué clairement, avec mon père, les raisons des son départ d'Italie. Ce sont probablement des raisons économiques et politiques.

Il parlait bien le français, avait probablement un accent que nous n'entendions pas, et lisait bien notre langue. Il travaillait dans une carrière comme tailleur de pierre, avec de nombreux italiens venant de toutes les provinces, beaucoup étant des réfugiés politiques. Parfois, aux beaux jours, ils se retrouvaient à la maison pour chanter des chansons italiennes accompagnés de mandolines ou de guitares. Je ne sais quelle langue commune ils avaient car beaucoup ne parlaient que leur dialecte mais ils se compre- 
En hommage à mon amie Michelle Sommers, cette petite histoire vraie

N. TOFFOLETTI naient. Il y avait un Sarde dit "le sardignol".

Nous n'avons jamais parlé italien à la maison, mon père ne voulant que parler français avec nous. J'ai dû attendre le lycée pour apprendre cette langue dont je connaissais déjà la musicalité.

Je n'ai retenu qu'une comptine qui "faisait passer le hoquet si on la disait d'un trait": sangloce arbe di poce arbe di taglia sangloce pui non dai. Quel en est le sens exact? J'essaie de transcrire ce dont je me souviens des seules paroles transmises par mon père. J'imagine que c'était du dialecte local. Je n'ai jamais osé en parler à mon professeur d'italien, que pourtant j'adorais.

Mon père est mort à 55 ans sans avoir jamais revu son village. Nous n'avions pas les moyens financiers pour lui permettre ce voyage.

À sa retraite, ma mère est allée visiter le pays et le village de naissance de son mari. Elle a été accueillie par un neveu, décédé depuis; il habitait la maison familiale à Faedis, maison nichée au fond d'un hameau.

L'an passé mes deux sœurs, mon frère et moi avons décidé d'aller à Faedis dont nous n'avions plus aucune nouvelle depuis longtemps. Toute la famille italienne avec laquelle nous correspondions de temps en temps a peu à peu disparu. Début mai 2014 nous avons pris l'avion pour Venise, puis loué un minibus pour aller à Udine et Faedis. Nous étions sept personnes à faire le voyage.

Après avoir visité Udine nous avons filé sur Faedis. Nous avons obtenu des renseignements à la mairie: la maison familiale était encore habitée par Franca, la fille du neveu rencontré par ma mère. Le hameau est très excentré, au bout d'une petite route qui ne va pas plus loin. Ce fut difficile à trouver, mais notre cousine Franca semblait bien connue de tous les gens à qui nous demandions des renseignements. Arrivés à la maison dont nous ne connaissions que le numéro, nous sommes tous descendus. J'ai demandé à un passant s'il connaissait notre cousine. Il est entré dans une maison et en est ressorti accompagné d'une petite dame, tablier et torchon à la main, l'air complètement interloqué. C'était son épouse et notre cousine Franca.

Décrire la stupéfaction de cette femme devant l'arrivée de ces cousins français inconnus est impossible. Des photos ont immortalisé ce moment.

Les présentations donnèrent lieu à des embrassades, des sourires, des rires et... quelques larmes d'émotion.

Nous avons visité la maison, le jardin, écouté l'histoire de la famille racontée par Franca, puis nous avons poursuivi au restaurant 
En hommage à mon amie Michelle Sommers, cette petite histoire vraie

N. TOFFolettI où nous avions convié nos nouveaux cousins. Ce fut le moment de raconter nos vies, Franca est très bavarde et je suis la seule à parler italien!!!

À Faedis tout est écrit en italien et en frioulan, deuxième langue officielle, tous les habitants sont donc bilingues, nous avons lu notre nom sur de nombreux édifices municipaux. Je n'ai jamais parlé italien avec mon père, il était décédé quand en quatrième j'ai choisi italien en seconde langue. J'aimais tellement cette langue qu'au bac je l'ai désignée comme première. J'ai également étudié l'anglais, puis un peu, le russe, l'espagnol; mais je garde une tendresse toute particulière pour ma langue "paternelle".

Mon fils, hélas, ne parle pas italien mais il est un polyglotte accompli puisqu'il parle couramment six langues étrangères dont le chinois (il est marié à une chinoise et vit à Shanghai). Il n'a pas encore d'enfant.

Dans notre famille nous comptons des portugais, des espagnols, des vietnamiens, des italiens, des chinois. Nous sommes une nombreuse famille polyglotte et plurielle, très heureuse d'être tout cela à la fois. 